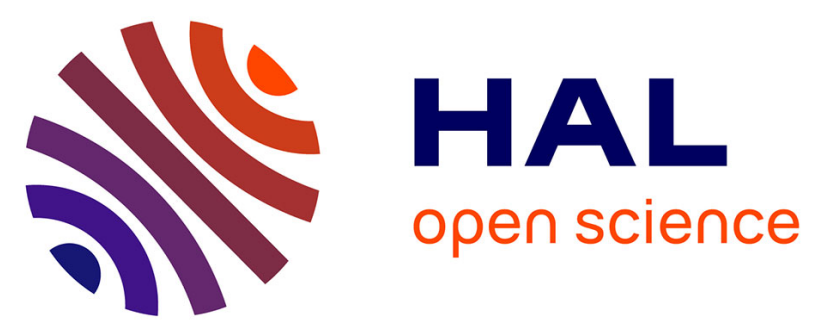

\title{
Exposure of pregnant women to organophosphate insecticides and child motor inhibition at the age of 10-12 years evaluated by fMRI
}

Anne-Claire Binter, Elise Bannier, Dave Saint-Amour, Grégory Simon, Christian Barillot, Christine Monfort, Sylvaine Cordier, Fabienne Pelé, Cécile Chevrier

\section{To cite this version:}

Anne-Claire Binter, Elise Bannier, Dave Saint-Amour, Grégory Simon, Christian Barillot, et al.. Exposure of pregnant women to organophosphate insecticides and child motor inhibition at the age of 10-12 years evaluated by fMRI. Environmental Research, 2020, 188, pp.109859. 10.1016/j.envres.2020.109859 . inserm-02932111

\section{HAL Id: inserm-02932111 https://www.hal.inserm.fr/inserm-02932111}

Submitted on 10 Sep 2020

HAL is a multi-disciplinary open access archive for the deposit and dissemination of scientific research documents, whether they are published or not. The documents may come from teaching and research institutions in France or abroad, or from public or private research centers.
L'archive ouverte pluridisciplinaire HAL, est destinée au dépôt et à la diffusion de documents scientifiques de niveau recherche, publiés ou non, émanant des établissements d'enseignement et de recherche français ou étrangers, des laboratoires publics ou privés. 
1 Exposure of pregnant women to organophosphate insecticides and child motor

2 inhibition at the age of 10 to 12 years evaluated by fMRI

3 Binter A.C ${ }^{1}$, Bannier ${ }^{2}$, Saint-Amour $\mathrm{D}^{3}$, Simon $\mathrm{G}^{4}$, Barillot $\mathrm{C}^{5}$, Monfort $\mathrm{C}^{1}$, Cordier $\mathrm{S}^{1}$, Pelé $\mathrm{F}^{1,6^{*}}$,

4 Chevrier $\mathrm{C}^{1^{*}}$

$5{ }^{1}$ Univ Rennes, Inserm, EHESP, Irset (Institut de recherche en santé, environnement et travail) -

6 UMR_S 1085, F-35000 Rennes, France

$7{ }^{2}$ Univ Rennes, CHU Rennes, CNRS, Inria, Inserm, IRISA UMR 6074, Empenn - ERL U 1228, F-35000

8 Rennes, France

$9{ }^{3}$ Department of Psychology, Université du Québec à Montréal, Montréal, Canada

$10{ }^{4}$ ISTS EA 7466, University of Caen Normandie, Caen, France

$11{ }^{5}$ Univ Rennes, CNRS, Inria, Inserm, IRISA UMR 6074, Empenn - ERL U 1228, F-35000 Rennes, France

$12{ }^{6}$ Univ Rennes, Inserm, ClC 1414, Rennes, France

$13 *$ Equal contributors

14 Correspondence address: Inserm UMR 1085 Irset, 9 Avenue du Pr. Léon Bernard, 35000 Rennes,

15 France, anne-claire.binter@gmail.com

16 Conflict of interest: The authors declare they have no actual or potential competing financial 17 interests. 
18 Highlights

19 - Organophosphates (OP) are widely used in agricultural and domestic settings.

20 - Adverse neuro-outcomes were linked to OP exposure but underpinnings are unknown.

21 - Functional MRI was performed for 95 children aged $10-12$ years.

22 - Activity in frontal regions decreased with increasing levels of OP metabolites.

23 - OP may be associated with altered activity in brain regions related to inhibition.

\section{Abstract}

25 Background: Organophosphate pesticides (OP) are widely used for both agricultural and domestic 26 purposes. Epidemiological studies suggest neurotoxicity in children after exposure to

27 organophosphates pesticides (OP) at low levels but possible mechanism is still unclear.

28 Objectives: We aimed at investigating the effects of prenatal exposure to OPs on inhibitory control of

2910 to 12 year-old-children assessed by a motor inhibition task during functional magnetic resonance 30 imaging (fMRI).

31 Methods: Ninety-five children from the PELAGIE cohort (Brittany-France, from 2002) underwent an

32 fMRI examination during which inhibition was assessed by a Go/No-Go task. Task performance was

33 assessed by average response latency, commission rate and composite performance score (PS).

34 Whole brain activation was estimated by modeling the hemodynamic response related to inhibition

35 demand and successful inhibition. OP exposure was assessed by measuring six dialkylphosphate

36 (DAP) metabolites in the urine of women in early pregnancy (<19 WG). Concentrations were summed

37 to obtain overall levels of diethylphosphate (DE), dimethylphosphate (DM) and total non-specific 38 metabolites (DAP), standardized to homogenize sampling conditions and categorized into levels of 39 exposure: low (reference), moderate or high. Regression models were adjusted for potential 40 cofounders considered by restriction and statistical criteria.

41 Results: Moderate levels of DAP were associated with a decreased commission rate $(\beta=-6.65 \%, p=$ 42 0.04), indicating improved performance. Increasing levels of DM and DE were associated with 43 decreased brain activity in the left inferior and bilateral superior frontal regions during successful 44 inhibition. We did not observe any differential activation related to inhibitory demands.

45 Discussion: These results suggest that prenatal OPs may be associated with altered pattern of brain 46 activity in regions related to inhibition among children and need to be confirmed by additional 47 studies. 


\section{Keywords:}

49 prenatal exposure, organophosphates, neurodevelopment, motor inhibition, fMRI 


\section{Introduction}

51 Organophosphate pesticides (OPs) have been used worldwide since the 1970's for agricultural and

52 pest control purposes due to their high acute neurotoxicity for insects and shorter environmental

53 persistence than that of the organochlorine insecticides they substituted. Their half-life is limited

54 from a few days to several months depending on the environmental conditions. However, they are

55 frequently found, as parent compounds or degradation products, in both outdoor and indoor French

56 environments (Coscollà et al. 2017; Raffy et al. 2017). A common exposure pathway of the general

57 population is thought to be the ingestion of food or drinking water contaminated with

58 organophosphate residues. A study of the typical French diet among pregnant women in 2011

59 estimated the daily intake of OP residues (including chlorpyrifos) to be sufficient to present a

60 potential risk of neurochemical effects (de Gavelle et al. 2016). Other sources of exposure including

61 the use of household insecticides or living close to areas where OP insecticides are used for

62 agriculture, are very likely in France (Raffy et al. 2017). Since the 2000's, various mixtures of OPs or

63 their metabolites have been frequently found in human biomonitoring studies, in particular in the

64 urine or hair matrices of pregnant French women and children, suggesting widespread and repeated OP exposure (Béranger et al. 2018; Cartier et al. 2016; Dereumeaux et al. 2016).

The primary neurotoxic property of organophosphate compounds for insect control is the inhibition of acetylcholinesterase (AChE) activity in synaptic junctions, resulting in hyper-excitability of the nervous system. Similar effects have also been described in humans after accidental acute exposure. Other neurotoxic mechanisms of OPs have then been described at low doses including noncholinergic effects, such as oxidative stress, neuro-inflammation, the alteration of axonal transport and mitochondria metabolism, the loss of neurons and glia, and persistent serotonergic effects (Chen et al. 2017; Slotkin and Seidler 2005; Terry 2012).

73 Low-dose exposure is a matter of concern, especially during prenatal and childhood periods.

74 Biomonitoring studies have reported organophosphate metabolites to be found in the placenta, cord blood and meconium matrices, suggesting the ability of OPs to cross the placental barrier (Silver et al. 2017; Whyatt R M and Barr D B 2001). Given the vulnerability of the developing blood-brain-barrier especially during fetal life (Eskenazi et al. 1999; Gupta et al. 1999; Rice and Barone 2000), the epidemiological literature investigating potential adverse neurodevelopmental effects following prenatal exposure to OPs is extensive.

80 Although a variety of outcomes has been investigated, several studies have reported adverse effects 81 on specific cognitive and behavioral functions that suggest possible alteration of executive functions 82 (González-Alzaga et al. 2014; Koureas et al. 2012; Muñoz-Quezada et al. 2013). Most of published 
studies used neuropsychological tests or standardized questionnaires. We assume that the investigation of functional brain processes while children are engaged in inhibitory cognitive processes, suspected to be affected by OPs, has the potential to provide mechanistic insights into such processes. Task-related functional magnetic resonance imaging (fMRI) is one way to measure cerebral activity during cognitive activity (Horton et al. 2014). A recently published pilot study used functional near-infrared spectroscopy (fNIRS) to investigate neural activity in Mexican-American adolescents from the CHAMACOS cohort (Sagiv et al. 2019). FNIRS is based on the same technique as fMRI, in which changes in neurovascular coupling during cerebral activity are detected. They reported associations between prenatal exposure to OP and altered activation pattern during tasks involving executive functions and language comprehension. There was a bilaterally decreased activity in the inferior frontal cortex during tasks of cognitive flexibility and working memory, which are two executive functions.

Among executive functions, inhibitory control is critical for learning (Bari and Robbins 2013) and difficulties in the ability to control and inhibit a prepotent response can lead to various developmental challenges, such as ADHD (Willcutt et al. 2005) and poor academic performance (Diamond et al. 2007). Our aim was to assess the association between prenatal exposure to OP evaluated by maternal urinary biomarkers, and inhibitory control of 10- to 12-year-old children from a population-based mother-child cohort using fMRI during a motor inhibition task.

\section{Materials and Methods}

\section{Study Population}

The PELAGIE (Perturbateurs endocriniens: Etude Longitudinale sur les Anomalies de la Grossesse, I'Infertilité et l'Enfance) is a population-based mother-child cohort which included 3,421 women before 19 weeks of gestation from three districts of Brittany (France) between 2002 et 2006 (Garlantézec et al. 2009). They were recruited by obstetricians, gynecologists, and ultrasonographers at early visits for prenatal care. At inclusion, they completed a self-administered questionnaire about family, social, and demographic characteristics, diet, and lifestyle and sent a urine sample to the laboratory. At delivery, midwives and pediatricians at the maternity units provided with information from medical records about the pregnancy, delivery, and neonatal health. Questionnaires given when their children were two and six years old allowed recording further information about the lifestyle, development and health of the child.

A sub-cohort of 251 children between 10 and 12 years of age was randomly selected for the present study to include approximatively 100 children. Children had to be born at term (delivery $\geq 35$ weeks 
116 of amenorrhea (WA)) and present no major condition at birth (neonatal hospitalization,

117 hypoglycemia, or five-minute Apgar score $<7$ ), nor prenatal exposure to tobacco, alcohol, or medical

118 treatment during childhood which could affect neurodevelopment (methylphenidate, psychotropic, 119 or antiepileptic drugs, etc.) (Cartier et al. 2016). Among them, 124 (49.4\%) families refused to participate or were lost to follow-up, $26(10.3 \%)$ were excluded due to technical (braces) or medical (meningitis, or head trauma requiring medical supervision) reasons. Thus, 101 (40.2\%) children participated in the neuropsychological and fMRI examinations. Urine samples were not available for six women because they were used for other urinary assays, resulting in 95 mother-child pairs for our study population (inclusion flowchart is shown in Figure 1).

At the time of follow-up, parents completed a questionnaire about the environmental conditions and health of their child. All parent and child participants provided written informed consent and the appropriate ethics committees approved the study.

\section{Organophosphate insecticide exposure assessment}

At inclusion, women returned a urine sample (first morning void) in a $10^{-} \mathrm{mL}$ test tube $(95 \times 16-\mathrm{mm}$ polypropylene, with wing plug). Six nonspecific dialkylphosphate (DAP), metabolites of numerous OPs were analyzed: dimethylphosphate (DMP), dimethylthiophosphate (DMTP), dimethyldithiophosphate (DMDTP), diethyl-phosphate (DEP), diethylthiophosphate (DETP), and diethyldithiophosphate (DEDTP). Analyses were performed in 2007-2008 $(n=54), 2013(n=22)$, and 2017 ( $n=19$ ) by liquid chromatography-electrospray ionization tandem mass spectrometry (LC/ MSMS) after solid-phase extraction (SPE) at the LABOCEA (Laboratoire public Conseil, Expertise et Analyse en Bretagne). Details of the chemical analysis procedures have been previously described (Cartier et al. 2016).

The limits of quantification (LOQ) for the chemical analyses performed in 2007-2008 (hereafter referred as series $n^{\circ} 1$ ) were $1.25,1.7,0.02,0.2,1$, and $0.45 \mu \mathrm{g} / \mathrm{L}$ for DEP, DETP, DEDTP, DMP, DMTP, and DMDTP, respectively. Values between the limit of detection (LOD) and the LOQ were available for series $n^{\circ} 2$ and $n^{\circ} 3$ analyzed in 2013 and 2017, respectively. The LODs were 0.2, 0.1, 0.005, 0.06, 0.32, and $0.13 \mu \mathrm{g} / \mathrm{L}$ for DEP, DETP, DEDTP, DMP, DMTP, and DMDTP, respectively. The mass concentrations were converted to molar concentrations using the molecular masses $(\mathrm{g} / \mathrm{mol})$ from Toxnet database: DEP (CAS number 598-02-7) 154.101, DETP (CAS number 2465-65-8) 170.168, DEDTP (CAS number 52857-42-8) 186.235, DMP (CAS number 813-78-5) 126.0473, DMTP (CAS number 59401-04-6) 142.114, and DMDTP (CAS number 32534-66-0) 158.181. Concentrations were summed to obtain overall concentrations of diethylphosphate metabolites (DE: DEP, DETP, DEDTP), 
148 dimethylphosphate metabolites (DM: DMP, DMTP, DMDTP), and all nonspecific dialkylphosphate

149 metabolites (DAP).

150 Motor inhibition function

151 The Go/No-Go paradigm

152 The motor inhibition function of the children was evaluated using a 10-minute visual Go/No-Go task

153 completed in the MR scanner. First, a short practice run in front of a computer and then in a mock

154 MR scanner was performed to provide the instructions and accustom the child to the scanner 155 environment.

156 The event-related task, adapted from Mostofsky et al. (2003), minimizes cognitive demands other 157 than motor execution and response inhibition and can be easily performed in children (Suskauer et 158 al. 2008). Green and red smileys were rapidly presented on a screen, every $1.5 \mathrm{~s}$. Children were asked 159 to press a button as quickly as possible when seeing a green smiley but had to refrain otherwise. The 160 ratio of No-go cues (red smileys) over Go cues (green smileys) was 1:4, to elicit a dominant motor 161 response. The task was implemented using E-Prime v.2.0.8 Professional (Psychology Software Tools, 162 Pittsburgh, PA, USA) and presented using the Nordic Neurolab Solution (Nordic Neurolab, Bergen, 163 Norway).

164 The task was split into two runs of five minutes each, composed of 150 trials ( 123 Go and 27 No-Go 165 cues) and four 10-second rest periods a run. A trial consisted of the consecutive presentation of a cue 166 (duration of $200 \mathrm{~ms}$ ) and a cross fixation point (duration of 1,300 ms). A response was allowed until 167 the next trial began, giving a constant inter-stimulus interval of 1,500 ms. Smileys appeared in a 168 pseudo-random order: cues at the beginning of runs or following resting periods had to be Go cues. 169 Go cues had to occur at least three times in a row and No-Go cues had to occur at most two times in 170 a row.

171 Performance indicators at the Go/No-Go task

172 Child performance was evaluated by response latency (average reaction time for the correct 173 answering of Go cues), commission rate (incorrect answers for the No-Go cues), and a composite 174 performance score. Responses occurring during cue presentation (before $200 \mathrm{~ms}$ ) were considered 175 anticipatory and were excluded from the indicator calculation (on average, less than $1 \%$ of all cues). 176 The accuracy of motor inhibition was assessed by the sensitivity index, $d^{\prime}$, which subtracts the 177 standardized ( $z$ score) commission rate from the standardized hit rate (correct answers for Go cues). 178 The response latencies and commission errors inversely correlated with each other (Spearman rho 179 coefficient $=-0.31, p<0.01$ ). Thus, in order to combine both response speed and accuracy into a 180 single score, we built a composite performance score by subtracting the response latencies from the 
181 accuracy of motor inhibition $\left(d^{\prime}\right)$, following standardization, based on the work of Collignon et al. 1822010.

183 Thus, children with the high scores were considered to efficiently perform the task (fast with a high

184 hit rate, with few commissions), whereas children with the lowest scores were considered to be slow 185 and found it difficult to inhibit their response to No-Go cues. Performance indicators were missing 186 for two children (resulting in $n=93$ included children), due to technical issues with the recording.

187 Cerebral hemodynamic response related to the task

188 Scanning was performed on a 3 T MR Scanner (Magnetom Verio, VB17, Siemens, Erlangen, Germany) 189 using a 32-channel receiver head coil.

190 High-resolution 3D anatomical images were obtained using T1-weighted MPRAGE at $1 \mathrm{~mm}^{3}$ 191 resolution for anatomical referencing (repetition/inversion/echo times: 1,900/900/2.26 ms, $9^{\circ}$ flip 192 angle).

193 Functional images were acquired using gradient echo-planar imaging (EPI) with repetition/echo times 194 of 2,500/30 ms, a $90^{\circ}$ flip angle, and 110 volumes per run. Each volume was composed of 34 axially 195 oriented $4 \mathrm{~mm}$-interleaved slices, covering the entire brain. Scans were based on a $110 * 110$ 196 acquisition matrix $\left(220 \times 220 \mathrm{~mm}^{2}\right.$ field of view), with a voxel size of $2 * 2 * 4 \mathrm{~mm}^{3}$. Operators assessed 197 image quality during the acquisition and two children who moved repeated the sequence. Learning 198 effects are not expected for this task and we did not observe any improvement in performance 199 during the two sessions.

200 Image pre-processing is described in Supplementary Material. Head movements were evaluated by 201 six parameters calculated during the realignment step. Three children had head motion greater than $2022 \mathrm{~mm}$ (in-plane size of an acquisition voxel) and they were excluded from further image analysis 203 (resulting in $\mathrm{n}=92$ included children).

204 The blood oxygen level dependent (BOLD) response was estimated from trials (Go cue and No-Go 205 cue) and motion regressors, with an implicit baseline corresponding to resting periods (enabling 206 recovery of the hemodynamic response) and the time between trials, using a canonical 207 hemodynamic response function (HRF) and its temporal derivative. This HRF is the subtraction of two 208 gamma functions, the first modelling the peak of intensity, with a latency of $6 \mathrm{~s}$, and the second one 209 the undershoot during the recovery period, with a latency of $16 \mathrm{~s}$. The use of a temporal derivative 210 allows for variations in peak latency, while providing comprehensive models for the response. 211 Scanner drift was modeled with a discrete cosine transform (DCT) set (128-second cut off) and 212 temporal autocorrelation was accounted for using an autoregressive $A R(1)$ model over the entire 
213 brain. First, we modeled Go cues and No-Go cues, independently of the subject's response. Secondly,

214 we modeled successful No-Go, Go, and failed No-Go conditions. Maps were extracted for each

215 condition and each subject by voxel-wise multiple linear regressions estimated by the restricted

216 maximum likelihood (ReML) method and then contrasted. We built two types of individual contrast

217 images, as we were investigating the ability to stop a planned response when it is no longer

218 pertinent. First, we extracted "No-Go vs Go" activations, representing activation amplitudes that

219 were higher for inhibition than motor tasks, when children perceived the inhibition demand.

220 Secondly, we built contrast images for "Successful No-Go vs successful Go", when children were able

221 to inhibit and stop their answers, expected to reflect successful inhibition. There were no differences

222 between the two runs for contrast estimates (at the uncorrected cluster level $p<0.001$ ) or any

223 performance indicators (at $p<0.05$ ), allowing concatenation of the two runs.

224 Statistical analysis strategy

225 Standardization of sampling conditions and imputation

226 Sampling conditions of urinary samples of the present study are heterogeneous, in particular duration of storage due to three different chronological series of analyses (2007-2008, 2013 and 2017). Biomarker concentrations may vary according to sampling conditions. Thus, we aimed to standardize the urinary concentrations of DAP under various sampling conditions to limit their possible influence in the association study.

231 We adapted a standardization method based on regression residuals previously described by

232 Mortamais et al. (Mortamais et al. 2012). First, we estimated the influence of sampling conditions

233 (sampling day, duration of storage before and after freezing, and creatinine levels) using an adjusted

234 Tobit regression model to account for multiple censored data. We adjusted the Tobit models for the

235 year and season of sampling, as these parameters may be associated with the true level of exposure

236 and reflect temporal variation of OP uses and exposure. Then, left-censored data (values below the

237 LOD) were imputed from a log-normal distribution (Jin et al. 2011). Last, imputed concentrations

238 were standardized using Tobit model estimates as if urines had been sampled under the same

239 conditions (i.e., week-day collection, freezing before $24 \mathrm{~h}$ after collection, duration of storage $<5$

240 years and median creatinine concentration).

241 All OP metabolite concentrations used in further statistical analyses were imputed for values below

242 the LOD or LOQ and standardized for sampling conditions (sampling day, duration of storage and

243 creatinine levels) unless specified otherwise. DAP levels were categorized into three groups: for DAP

244 and DM in terciles, and for DE (with > 33\% of values < LOD), values < LOD, values > LOD, and <

245 median, values > median. For clarity, we refer hereafter to low, moderate, or high levels of exposure. 
247 Multivariable linear regression models were built on performance indicators (log-transformedresponse latency, commission rate, and performance score) to analyze the association with each categorical level of OP metabolite. We used restricted cubic splines with log-transformed metabolite concentrations to assess a possible dose-response relation. When checking for the assumption of linearity, we plotted urinary metabolite levels as continuous.

252 The BOLD response during the motor inhibition task was modeled by mixed effect generalized linear regression models to investigate the effect-modification of the prenatal exposure to OP by the motor inhibition task on cerebral activity. We did not have any a priori hypotheses on brain regions that could be differentially activated during the inhibition task across exposure levels and thus performed whole-brain analyses. We then concentrated our interpretation on the regions known to be part of the motor inhibition network (frontal and anterior cingular cortices and supplementary motor area (SMA)) regions (Mostofsky et al. 2003; Suskauer et al. 2008) and also consider other brain regions, such as those than can be involved in ancillary processes (e.g. attention, vision). Statistical significance was assessed for cluster-wise significance, defined by random field theory (FWER corrected $p=0.05$ ) to account for 3D spatial autocorrelation, using an uncorrected one-sided clusterdefining threshold of $p=0.01$ (Nichols and Hayasaka 2003).

Then, we applied our linear regression models to all the children stratified by sex to investigate whether the association between OP metabolite levels and motor inhibition differ according to the sex of the child.

\section{Potential cofounders}

267 Potential adjustment variables were selected from lifestyle and socioeconomic variables collected at 268 inclusion (i.e. maternal age, maternal educational level, pre-pregnancy BMI, pre-pregnancy tobacco 269 consumption, fruit and vegetable consumption and fish consumption during pregnancy), from 270 medical records at delivery (i.e. pregnancy pathologies, child's sex, or during follow-up (i.e. duration 271 of non-exclusive breastfeeding, parity, child's educational level and child's lateralization at follow272 up). They were included in all regression models if they were associated (at $p<0.10$ ) with both OP 273 metabolite levels and motor inhibition performance (see Supplementary Material, Table S.3); only 274 breastfeeding ( $\leq$ vs $>3$ months) met the criteria. Fruit and vegetable intake was also forced in all 275 regression models ( $<v s \geq 3$ portions a day), as this has been described to be a possible source of DAP exposure (Sudakin and Stone 2011). 
Sensitivity analyses

278 Two sets of sensitivity analyses were performed. The first one excluded two children with extreme

279 performance scores (statistical outliers outside averaged performance score $\pm 3^{*}$ standard errors interval), and the second included OP metabolite levels imputed for values below the LOD but not standardized for sampling conditions.

282 R software v.3.5.1 (https://www.R-project.org/) and SPM12 (http://www.fil.ion.ucl.ac.uk/spm/) were 283 used for data analysis.

\section{Results}

\section{Population characteristics}

286 All pregnant women included in the study were of European origin (Table 1). At inclusion, they had a 287 median age of 30.4 years, were highly educated $(46.8 \%$ attended at least three years of post288 secondary school) and declared to be employed (91.6\%). Two thirds declared to be non smokers 289 before inclusion. These women reported few medical problems during pregnancy (3.2\% reported 290 high blood pressure, no diabetes). They gave birth mainly to girls (56.8\%), with a median birth weight 291 of $3,430 \mathrm{~g}$ and $43.2 \%$ of the children were breastfed more than three months. Their children at the follow-up time of the present study were mostly right-handed (87.4\%), had a median age of 10.8 years, and most attended elementary school (72.6\%). We did not observe any differences between the study population and non-participants for these characteristics (see Supplementary material, Table S.1).

\section{Urinary OP metabolite levels}

297 OP metabolites were detected in the urine of $57 \%$ of the pregnant women for $D E, 86 \%$ for DM and

$29895 \%$ for all DAP compounds with respective median values of $0.8,31.8$, and $44.4 \mu \mathrm{M}$ (see 299 Supplementary material, Table S.2).

300 Increased creatinine concentrations were associated with increased levels of DE metabolites $\left(1.10^{-4}\right.$ $301 \mu \mathrm{M}$ for an increase of one $\mu \mathrm{M}$ of creatinine, $\mathrm{p}=0.02$ ). A moderate duration of storage before freezing (24-48 h) versus a short $(<24 h)$ duration was associated with increased DM metabolite levels $(p<0.01)$ and a moderate duration of storage after freezing $(5-10$ years) versus a short $(<5$ years) duration was associated with decreased DM metabolite concentrations $(p<0.01)$. We found no statistically significant association between sampling conditions and DAP metabolite levels nor difference with sampling day (weekday vs weekend) for any OP metabolite (see Supplementary

307 Material, Table S.2). There was an association between analyses series and DAP metabolites ( $\beta=-1.0$

308 for series 2 vs series 1 and $\beta=0.3$ for series 3 vs series 1 , global $p=0.03$ ), for DM metabolites $(\beta=$ 3092.6 for series 2 vs series 1 and $\beta=0.3$ for series 3 vs series 1 , global $p<0.001$ ) and not for DE 
310 metabolites ( $\beta=0.06$ for series 2 vs series 1 and $\beta=-0.34$ for series 3 vs series 1 , global $p=0.91$ ) (see

311 Supplementary Material Figure S.I and Table S.2).

312 As expected, differences did not remain statistically significant after standardization of sampling 313 conditions (for DAP, $p=0.82$; for DM, $p=0.23$ ) (see Supplementary Material Figure S.I). The median

314 standardized OP metabolite levels presented were $0.8 \mu \mathrm{M}, 17 \mu \mathrm{M}$, and $25 \mu \mathrm{M}$ for $\mathrm{DE}$, DM, and DAP,

315 respectively (see Supplementary Material Table S.3).

316 Performance indicators and brain activation during the task

317 Children performed the Go/No-Go task with a median commission rate of $25.9 \%$, and reaction time 318 of $399.6 \mathrm{~ms}$. The performance score ranged from -9.8 to 2.1, with a median of 0.3 (see 319 Supplementary Material Table S.3).

320 For "No-go vs Go" and "Successful No-Go vs successful Go" contrasts in the brain, children showed 321 activation in regions known to be involved in the motor inhibition network: the anterior 322 cingulate/SMA and inferior and middle frontal regions of both hemispheres. These contrasts were 323 also associated with activated clusters in the right middle temporal region and brain structures of 324 both hemispheres (occipital and parietal region, posterior lobe of the cerebellum, caudate nucleus, 325 and putamen) (see Supplementary Material, Table S.4 and Table S.5).

326 Prenatal urinary organophosphate metabolite levels and motor inhibition

327 There was an association between moderate levels of DAP and decreased commission rate $(\beta=-$ $3286.65 \%$, 95\% confidence interval $(\mathrm{Cl})$ : $-12.83 ;-0.48)$, without a statistically significantly higher 329 performance score $(\beta=0.33, \mathrm{Cl}:-0.49 ; 1.15)$. There was a trend towards a lower performance score $330(\beta=-0.76, \mathrm{Cl}:-1.56 ; 0.03)$ and longer response latency $\left(\beta=\left(e^{0.08}-1\right) * 100=8 \%, \mathrm{Cl}: 0 ; 16\right)$ associated 331 with moderate DE levels. Children whose mothers had moderate urinary levels of DM metabolites had a lower commission rate $(\beta=-5.59)$, but the association was not statistically significant $(\mathrm{Cl}$ : 11.71; 0.53) (Figure 2). Our results did not show a linear dose-response relation between any child's inhibition performance indicators and maternal urinary OP metabolite levels when OP metabolite concentrations were used as continuous variables (Figure 2 and Supplementary material Figure S.II). The associations were similar for children of either sex, with no difference in the estimates, except for commission rate and moderate DE levels $(\beta=8.23, \mathrm{Cl}:-0.17 ; 16.63$ for girls $(n=53)$ and $\beta=-7.33$, Cl: $-15.98 ; 1.33$ for boys $(n=40))$.

The first set of sensitivity analyses, which excluded statistical outliers, confirmed the previous statistically significant associations observed between commission rate and moderate DAP levels. Most of the associations were similar in the second set of sensitivity analyses when the OP metabolite levels were not standardized for sampling condition, except that response latency was 
343 significantly higher for children whose mothers showed high DE urinary levels $(\beta=8 \%, \mathrm{Cl}: 0 ; 16)$ (see

344 Supplementary material Tables S.4 and S.5).

345 We did not observe any differential activation related to inhibition demand perception. We did not 346 observe any difference in the inhibition network, stratified by sex, except for girls, with decreased 347 brain activity in the medial superior frontal region in association with moderate levels of DM 348 metabolites see Supplementary Material, Table S.6).

349 When children succeeded in inhibiting their response, there was decreased activation in the left 350 inferior frontal regions associated with high urinary levels of DM metabolites. Children whose 351 mothers had moderate or high levels of DE metabolites exhibited a lower BOLD response in the left 352 and right frontal regions (Figure 3 and Table 2). We did not observe any differential brain activation 353 in girls when stratifying the analyses by sex. However, we observed decreased brain activity in the 354 frontal regions of boys whose mothers had high levels of DAP or DM metabolites or moderate 355 urinary levels of DE metabolites.

\section{Discussion}

357 The present study investigated the potential neurodevelopmental toxicity of prenatal exposure to OPs on motor inhibition function in a Brittany population-based cohort of children. We did not observe any major alterations of the children's performance on the Go/No-Go task. A decreased commission rate associated with moderate levels of DAP suggests better performance. There was no differential brain activation related to inhibitory demands, but we observed decreased cerebral activity related to successful inhibition in regions involved in the motor inhibition network.

Previous epidemiological studies investigating the neurodevelopmental effects of prenatal exposure to OP have suggested possible alterations in children's inhibitory control. In a recent pilot study, Sagiv et al. reported an association between prenatal exposure to OPs and altered patterns of brain activity during tasks of executive function and language comprehension using the fNIRS technique on 95 adolescents from a population of agricultural communities of the Salinas Valley in California (CHAMACOS study). They found null associations during the Go/No-Go task but reported decreased bilateral brain activation in the prefrontal cortex during a cognitive flexibility task (Sagiv et al. 2019). In the CHAMACOS study, prenatal exposure to OP was also assessed by two maternal urinary samples collected during the first and second halves of pregnancy. The mothers had higher levels of DAP (109 nM DAP, 17.7 nM DE and 76.8 nM DM) than the present study. The authors reported statistically greater attention problems, ADHD, and K-CPT ADHD Confidence Index scores for fiveyear-old children $(n=323)$ and a similar but non-significant association at 3.5 years of age (Marks et al. 2010). Furlong et al. investigated the association between prenatal exposure to OP and 
neurodevelopmental phenotypes in six- to nine-year-old children $(n=141)$ at the Mount Sinai

377 Children's Environmental Health Center. Exposure was assessed by analyzing maternal urine

378 collected between 25 and 40 weeks of gestation. Urinary levels were higher than in the PELAGIE cohort (median of $37.1 \mathrm{nM}$ DM and 16.6 nM DE). They reported positive associations between DM metabolite levels and executive functioning factor scores. The impulsivity and externalizing factor score was not associated with maternal urinary levels of DE or DM (Furlong et al. 2017). A crosssectional study investigated the effect of prenatal and postnatal exposure to OP insecticides on the neurodevelopment of six- to eight-year-old Ecuadorian primary school children $(n=84)$ and reported a borderline significant association between reaction time and attention test scores and the children's current exposure (Harari Raul et al. 2010). A cross-sectional study evaluated the effects of methyl-parathion (MP) exposure during childhood on six-year-old-children living in Mississippi and Ohio. Exposed children $(n=132)$ were more prone to attention, and behavioral skill problems than controls $(n=147)$. However, the results were not consistent between the two sites of the study (Ruckart et al. 2004). Although they were not specifically investigating inhibition function, the results of Rauh et al. showing that seven-year-old children with high prenatal exposure to chlorpyrifos had frontal cortical thinning, also suggest brain alterations in the frontal cortex, involved in inhibition (Rauh et al. 2012). Findings of brain alterations after prenatal exposure to OPs are supported by one animal study that exposed gestational dams to $5 \mathrm{mg} / \mathrm{kg} /$ day chlorpyrifos during gestational days 13 to 17. At postnatal day 60 , the authors reported reduced neuron and glia count in anterior cingulate, prelimbic, and infralimbic areas of medial prefrontal cortex (mPFC), a region of the inhibition network, at levels showing no effect on body weight, organ coefficient, or pathological morphological changes (such as cytoplasm swelling, enlarged intercellular spaces, or cell apoptosis) in the mPFC (Chen et al. 2017).

Two major types of inhibitory control can be distinguished, cognitive and behavioral inhibition (Bari and Robbins 2013). The task we used involves behavioral response inhibition with a motor component. Response inhibition appears in early childhood and matures until adolescence (Luna and Sweeney 2006). Performance indicators in our population of 10- to 12-year-old children were similar to those reported during a similar Go/No-Go task with 8- to 13-year-old children (median response latency of $400 \mathrm{~ms}$ vs $407 \mathrm{~ms}$ and $25.9 \%$ vs $22 \%$ for commission errors) (Suskauer et al. 2008). We did not observe any differential performance score for the Go/No-Go task but observed decreased brain activity in frontal regions, known to be involved in inhibitory control. Children who are the most highly exposed to OP during pregnancy may present compensatory brain functioning to prevent problems of inhibition. However, we cannot eliminate the possibility that our neuropsychological indicators did not have sufficient sensitivity to discriminate the inhibitory capacity between the 
410 children. In the same way, we cannot rule out that our study $(n=95)$ lacks of statistical power to point

411 out any association, in particular with the sex-stratified analyses ( $n=41$ boys $/ n=54$ girls).

412 The motor inhibition network concerns three main regions: the anterior cingulate, SMA, and inferior

413 frontal gyri of both hemispheres (Aron 2007; Mostofsky et al. 2003). As expected, we observed

414 cerebral activation in these regions in the contrasts that we explored. We also observed additional

415 activation in other brain structures of both hemispheres (occipital and parietal region, posterior lobe

416 of the cerebellum, caudate nucleus and putamen). These regions are not part of the motor inhibition

417 network but have been described to be involved in certain motor inhibition tasks, in particular in 8-

418 to 13-year-old children (Suskauer et al. 2008). Activation observed in these brain areas may reflect

419 ancillary processes necessary for the Go/No-Go task, such as vision processing, attention and

420 decision making (Behrmann et al. 2004; Grahn et al. 2008; Rosen et al. 2018; Stoodley and

421 Schmahmann 2009). Nevertheless, BOLD imaging measures the ratio of deoxyhemoglobin to

422 oxyhemoglobin to indirectly evaluate neural activity. This indicator is commonly used, but may vary

423 depending on individual characteristics (blood flow, iron deficiency, etc.) and the performance of

424 inhibition is not determined solely by the intensity of the hemodynamic response but could also be

425 explained by brain structure, connectivity, etc. (Ogawa et al. 1990). Reduced activation may indicate

426 that exposure altered the recruitment of neural resources, such as a lack of neural fibers and/or

427 reduced connectivity of the inhibitory network. The associations observed between prenatal levels of

428 DM and DE metabolites and decreased activity from different regions of the brain may suggest an

429 alteration in the pattern of brain activity.

430 We observed no sex-specific effects on performance indicators but observed decreased brain activity

431 related to successful inhibition only in boys. This finding is consistent with the literature, which

432 suggests that boys may be more sensitive to OP exposure (Comfort and Re 2017; Marks et al. 2010).

433 In their review, Comfort and Re reported that sex-specific effects of OP exposure have been

434 commonly found in rodent studies. Whereas, the exact mechanisms of sex-dependent OP effects are

435 not fully established, authors assumed it could be the combination of altered morphology,

436 neuropeptide and neurotransmitter signaling, and neuroinflammation. They highlighted the

437 necessity to investigate this effect in epidemiological studies. Indeed, Marks et al. suggested an

438 increased risk of ADHD at five years of age in the CHAMACOS cohort in association with prenatal

439 exposure to OP in boys only.

440 Our study was based on a mother-child cohort (PELAGIE study) in which the longitudinal design

441 provides the opportunity to measure OP insecticide exposure during early pregnancy. We were also

442 able to consider lifestyle and socioeconomic factors by restriction or adjustment. In particular, 
443 children whose mothers reported alcohol or tobacco consumption during pregnancy were not

444 included in the study to eliminate two established risk factors of poorer neurodevelopment or 445 behavioral troubles in children (Yolton et al. 2014). We assessed prenatal exposure to OPs by maternal urinary biomarkers, which gives us the ability to capture all sources of exposure. We used $\mathrm{fMRI}$ to investigate brain functioning during an inhibition task in association with prenatal exposure to $\mathrm{OP}$ in the general population. This technique provides excellent spatial resolution, making it possible to investigate the potential effects of exposure in brain regions of only a few cubic millimeters.

Although we did not find any differences in the characteristics of our study population and nonparticipants, limiting the risk that a confounder may predict participation, the design of the PELAGIE cohort does not prevent a possible selection bias. Unlike the previously described epidemiological studies, the PELAGIE population does not include an ethnic minority and consists of participants with a high socioeconomic status. We cannot rule out the possibility that the stimulating environments and possible healthier lifestyles in our study population attenuated the potential neurotoxicity of OP exposure. The main limitation of our study was the exposure assessment, based on only one (first) morning void urinary sample collected during the first trimester of pregnancy, whereas OP insecticides have a short half-life, from several hours to several days (Costa 2018). It is likely that our measurement did not capture intra-individual variability, over time, due to the rapid metabolism and excretion of OP insecticides. This produces non-differential measurement errors in the exposure estimation. We could not explore the effects of OP exposure during late pregnancy or childhood, although human neurodevelopment is known to continue during childhood, until adolescence for maturation of the prefrontal cortex (Rice and Barone 2000). A recent study in the Netherlands, showing few effects of prenatal exposure to OP on nonverbal IQ in six-year-old children, suggests that late pregnancy may be a susceptible window for adverse effects on cognition (Jusko et al. 2019). DAP metabolites are found in food and dust. Thus, measurements of urinary levels of DAP may reflect intake of both the toxic parent OP compound and the metabolite itself, without possible distinction and biased exposure classification (Sudakin and Stone 2011).

\section{Conclusion}

We found no major alteration of neuropsychological scores in a French population-based cohort of 10 to 12 year-old-children with a high socioeconomic status, but found decreased brain activity in areas related to inhibition in association with prenatal exposure to OPs. These findings need to be confirmed by other studies and more deeply investigated by further neuroimaging techniques of morphometry, and functional or structural connectivity. 


\section{Acknowledgements}

477 We are grateful to the gynecologists, obstetricians, ultra-sonographers, midwives, pediatricians, and

478 families who participated in the study. We particularly thank Catherine Ducassoux, the MR 479 technicians, and the clinical investigation unit of Rennes hospital for neuropsychological and MRI 480 testing.

481 This study is supported by the Fondation de France (FdF) and Rennes University Hospital. The 482 PELAGIE cohort is funded by Inserm, the French Ministries of Health, Labor, and Ecology, InVS, ANR, 483 and ANSES. MRI data acquisition was performed at the Neurinfo MRI research facility of the 484 University of Rennes I. Neurinfo is funded by the European Union (FEDER), the French State, the 485 Brittany Council, Rennes Metropole, Inria, Inserm, and the University Hospital of Rennes. 


\section{References}

Aron AR. 2007. The Neural Basis of Inhibition in Cognitive Control. The Neuroscientist 13:214-228; doi:10.1177/1073858407299288.

Bari A, Robbins TW. 2013. Inhibition and impulsivity: behavioral and neural basis of response control. Progress in Neurobiology 108:44-79; doi:10.1016/j.pneurobio.2013.06.005.

Behrmann M, Geng JJ, Shomstein S. 2004. Parietal cortex and attention. Current Opinion in Neurobiology 14:212-217; doi:10.1016/j.conb.2004.03.012.

Béranger R, Hardy EM, Dexet C, Guldner L, Zaros C, Nougadère A, et al. 2018. Multiple pesticide analysis in hair samples of pregnant French women: Results from the ELFE national birth cohort. Environment International 120:43-53; doi:10.1016/j.envint.2018.07.023.

Cartier C, Warembourg C, Le Maner-Idrissi G, Lacroix A, Rouget F, Monfort C, et al. 2016. Organophosphate Insecticide Metabolites in Prenatal and Childhood Urine Samples and Intelligence Scores at 6 Years of Age: Results from the Mother-Child PELAGIE Cohort (France). Environ Health Perspect 124:674-680; doi:10.1289/ehp.1409472.

Chen XP, Chao YS, Chen WZ, Dong JY. 2017. Mother gestational exposure to organophosphorus pesticide induces neuron and glia loss in daughter adult brain. Journal of Environmental Science and Health, Part B 52:77-83; doi:10.1080/03601234.2016.1239973.

Collignon O, Girard S, Gosselin F, Saint-Amour D, Lepore F, Lassonde M. 2010. Women process multisensory emotion expressions more efficiently than men. Neuropsychologia 48:220-225; doi:10.1016/j.neuropsychologia.2009.09.007.

Comfort N, Re DB. 2017. Sex-specific Neurotoxic Effects of Organophosphate Pesticides Across the Life Course. Curr Environ Health Rep 4:392-404; doi:10.1007/s40572-017-0171-y.

Coscollà C, López A, Yahyaoui A, Colin P, Robin C, Poinsignon Q, et al. 2017. Human exposure and risk assessment to airborne pesticides in a rural French community. Science of The Total Environment 584-585:856-868; doi:10.1016/j.scitotenv.2017.01.132.

Costa LG. 2018. Organophosphorus Compounds at 80: Some Old and New Issues. Toxicol Sci 162:2435; doi:10.1093/toxsci/kfx266.

de Gavelle E, de Lauzon-Guillain B, Charles M-A, Chevrier C, Hulin M, Sirot V, et al. 2016. Chronic dietary exposure to pesticide residues and associated risk in the French ELFE cohort of pregnant women. Environment International 92-93:533-542; doi:10.1016/j.envint.2016.04.007.

Dereumeaux C, Saoudi A, Pecheux M, Berat B, de Crouy-Chanel P, Zaros C, et al. 2016. Biomarkers of exposure to environmental contaminants in French pregnant women from the Elfe cohort in 2011. Environment International 97:56-67; doi:10.1016/j.envint.2016.10.013.

Diamond A, Barnett WS, Thomas J, Munro S. 2007. Preschool Program Improves Cognitive Control. Science 318:1387-1388; doi:10.1126/science.1151148.

Eskenazi B, Bradman A, Castorina R. 1999. Exposures of children to organophosphate pesticides and their potential adverse health effects. Environmental Health Perspectives 107:409-419; doi:10.1289/ehp.99107s3409. 
Furlong MA, Herring A, Buckley JP, Goldman BD, Daniels JL, Engel LS, et al. 2017. Prenatal exposure to organophosphorus pesticides and childhood neurodevelopmental phenotypes. Environmental Research 158:737-747; doi:10.1016/j.envres.2017.07.023.

Garlantézec R, Monfort C, Rouget F, Cordier S. 2009. Maternal occupational exposure to solvents and congenital malformations: a prospective study in the general population. Occupational and Environmental Medicine 66:456-463; doi:10.1136/oem.2008.041772.

González-Alzaga B, Lacasaña M, Aguilar-Garduño C, Rodríguez-Barranco M, Ballester F, Rebagliato M, et al. 2014. A systematic review of neurodevelopmental effects of prenatal and postnatal organophosphate pesticide exposure. Toxicology Letters 230:104-121; doi:10.1016/j.toxlet.2013.11.019.

Grahn JA, Parkinson JA, Owen AM. 2008. The cognitive functions of the caudate nucleus. Progress in Neurobiology 86:141-155; doi:10.1016/j.pneurobio.2008.09.004.

Gupta A, Agarwal R, Shukla GS. 1999. Functional impairment of blood-brain barrier following pesticide exposure during early development in rats. Hum Exp Toxicol 18:174-179; doi:10.1177/096032719901800307.

Harari Raul, Julvez Jordi, Murata Katsuyuki, Barr Dana, Bellinger David C., Debes Frodi, et al. 2010. Neurobehavioral Deficits and Increased Blood Pressure in School-Age Children Prenatally Exposed to Pesticides. Environmental Health Perspectives 118:890-896; doi:10.1289/ehp.0901582.

Horton MK, Margolis AE, Tang C, Wright R. 2014. Neuroimaging is a novel tool to understand the impact of environmental chemicals on neurodevelopment. Curr Opin Pediatr 26:230-236; doi:10.1097/MOP.0000000000000074.

Jin Y, Hein MJ, Deddens JA, Hines CJ. 2011. Analysis of Lognormally Distributed Exposure Data with Repeated Measures and Values below the Limit of Detection Using SAS. Ann Occup Hyg 55:97-112; doi:10.1093/annhyg/meq061.

Jusko TA, van den Dries MA, Pronk A, Shaw Pamela A., Guxens Mònica, Spaan Suzanne, et al. 2019. Organophosphate Pesticide Metabolite Concentrations in Urine during Pregnancy and Offspring Nonverbal IQ at Age 6 Years. Environmental Health Perspectives 127:017007; doi:10.1289/EHP3024.

Koureas M, Tsakalof A, Tsatsakis A, Hadjichristodoulou C. 2012. Systematic review of biomonitoring studies to determine the association between exposure to organophosphorus and pyrethroid insecticides and human health outcomes. Toxicology Letters 210:155-168; doi:10.1016/j.toxlet.2011.10.007.

Luna B, Sweeney JA. 2006. The Emergence of Collaborative Brain Function: fMRI Studies of the Development of Response Inhibition. Annals of the New York Academy of Sciences 1021:296-309; doi:10.1196/annals.1308.035.

Marks AR, Harley Kim, Bradman Asa, Kogut Katherine, Barr Dana Boyd, Johnson Caroline, et al. 2010. Organophosphate Pesticide Exposure and Attention in Young Mexican-American Children: The CHAMACOS Study. Environmental Health Perspectives 118:1768-1774; doi:10.1289/ehp.1002056. 
Mortamais M, Chevrier C, Philippat C, Petit C, Calafat AM, Ye X, et al. 2012. Correcting for the influence of sampling conditions on biomarkers of exposure to phenols and phthalates: a 2step standardization method based on regression residuals. Environ Health 11:29; doi:10.1186/1476-069X-11-29.

Mostofsky SH, Schafer JG, Abrams MT, Goldberg MC, Flower AA, Boyce A, et al. 2003. fMRI evidence that the neural basis of response inhibition is task-dependent. Cognitive brain research 17: 419-430.

Muñoz-Quezada MT, Lucero BA, Barr DB, Steenland K, Levy K, Ryan PB, et al. 2013. Neurodevelopmental effects in children associated with exposure to organophosphate pesticides: A systematic review. Neurotoxicology 39:158-168; doi:10.1016/j.neuro.2013.09.003.

Nichols T, Hayasaka S. 2003. Controlling the familywise error rate in functional neuroimaging: a comparative review. Statistical Methods in Medical Research 12:419-446; doi:10.1191/0962280203sm341ra.

Ogawa S, Lee TM, Kay AR, Tank DW. 1990. Brain magnetic resonance imaging with contrast dependent on blood oxygenation. Proc Natl Acad Sci U S A 87: 9868-9872.

Raffy G, Mercier F, Blanchard O, Derbez M, Dassonville C, Bonvallot N, et al. 2017. Semi-volatile organic compounds in the air and dust of 30 French schools: a pilot study. Indoor Air 27:114127; doi:10.1111/ina.12288.

Rauh VA, Perera FP, Horton MK, Whyatt RM, Bansal R, Hao X, et al. 2012. Brain anomalies in children exposed prenatally to a common organophosphate pesticide. Proceedings of the National Academy of Sciences 109:7871-7876; doi:10.1073/pnas.1203396109.

Rice D, Barone S. 2000. Critical periods of vulnerability for the developing nervous system: evidence from humans and animal models. Environ Health Perspect 108:511-533; doi:10.1289/ehp.00108s3511.

Rosen ML, Sheridan MA, Sambrook KA, Peverill MR, Meltzoff AN, McLaughlin KA. 2018. The Role of Visual Association Cortex in Associative Memory Formation across Development. J Cogn Neurosci 30:365-380; doi:10.1162/jocn_a_01202.

Ruckart P, Kakolewski Kirsten, Bove Frank J, Kaye Wendy E. 2004. Long-term neurobehavioral health effects of methyl parathion exposure in children in Mississippi and Ohio. Environmental Health Perspectives 112:46-51; doi:10.1289/ehp.6430.

Sagiv SK, Bruno JL, Baker JM, Palzes V, Kogut K, Rauch S, et al. 2019. Prenatal exposure to organophosphate pesticides and functional neuroimaging in adolescents living in proximity to pesticide application. PNAS 201903940; doi:10.1073/pnas.1903940116.

Silver MK, Shao J, Zhu B, Chen M, Xia Y, Kaciroti N, et al. 2017. Prenatal naled and chlorpyrifos exposure is associated with deficits in infant motor function in a cohort of Chinese infants. Environment International 106:248-256; doi:10.1016/j.envint.2017.05.015.

Slotkin TA, Seidler FJ. 2005. The alterations in CNS serotonergic mechanisms caused by neonatal chlorpyrifos exposure are permanent. Developmental Brain Research 158:115-119; doi:10.1016/j.devbrainres.2005.06.008. 
Stoodley CJ, Schmahmann JD. 2009. Functional topography in the human cerebellum: A metaanalysis of neuroimaging studies. Neurolmage 44:489-501; doi:10.1016/j.neuroimage.2008.08.039.

Sudakin DL, Stone DL. 2011. Dialkyl phosphates as biomarkers of organophosphates: The current divide between epidemiology and clinical toxicology. Clinical Toxicology 49:771-781; doi:10.3109/15563650.2011.624101.

Suskauer SJ, Simmonds DJ, Fotedar S, Blankner JG, Pekar JJ, Denckla MB, et al. 2008. Functional magnetic resonance imaging evidence for abnormalities in response selection in attention deficit hyperactivity disorder: differences in activation associated with response inhibition but not habitual motor response. J Cogn Neurosci 20:478-493; doi:10.1162/jocn.2008.20032.

Terry AV. 2012. Functional consequences of repeated organophosphate exposure: Potential noncholinergic mechanisms. Pharmacology \& Therapeutics 134:355-365; doi:10.1016/j.pharmthera.2012.03.001.

Whyatt R M, Barr D B. 2001. Measurement of organophosphate metabolites in postpartum meconium as a potential biomarker of prenatal exposure: a validation study. Environmental Health Perspectives 109:417-420; doi:10.1289/ehp.01109417.

Willcutt EG, Doyle AE, Nigg JT, Faraone SV, Pennington BF. 2005. Validity of the Executive Function Theory of Attention-Deficit/Hyperactivity Disorder: A Meta-Analytic Review. Biological Psychiatry 57:1336-1346; doi:10.1016/j.biopsych.2005.02.006.

Yolton K, Cornelius M, Ornoy A, McGough J, Makris S, Schantz S. 2014. Exposure to neurotoxicants and the development of attention deficit hyperactivity disorder and its related behaviors in childhood. Neurotoxicology and Teratology 44:30-45; doi:10.1016/j.ntt.2014.05.003.

Bari A, Robbins TW. 2013. Inhibition and impulsivity: behavioral and neural basis of response control. Progress in Neurobiology 108:44-79; doi:10.1016/j.pneurobio.2013.06.005.

Behrmann M, Geng JJ, Shomstein S. 2004. Parietal cortex and attention. Current Opinion in Neurobiology 14:212-217; doi:10.1016/j.conb.2004.03.012.

Béranger R, Hardy EM, Dexet C, Guldner L, Zaros C, Nougadère A, et al. 2018. Multiple pesticide analysis in hair samples of pregnant French women: Results from the ELFE national birth cohort. Environment International 120:43-53; doi:10.1016/j.envint.2018.07.023.

Cartier C, Warembourg C, Le Maner-Idrissi G, Lacroix A, Rouget F, Monfort C, et al. 2016. Organophosphate Insecticide Metabolites in Prenatal and Childhood Urine Samples and Intelligence Scores at 6 Years of Age: Results from the Mother-Child PELAGIE Cohort (France). Environ Health Perspect 124:674-680; doi:10.1289/ehp.1409472.

Chen XP, Chao YS, Chen WZ, Dong JY. 2017. Mother gestational exposure to organophosphorus pesticide induces neuron and glia loss in daughter adult brain. Journal of Environmental Science and Health, Part B 52:77-83; doi:10.1080/03601234.2016.1239973.

Collignon O, Girard S, Gosselin F, Saint-Amour D, Lepore F, Lassonde M. 2010. Women process multisensory emotion expressions more efficiently than men. Neuropsychologia 48:220-225; doi:10.1016/j.neuropsychologia.2009.09.007. 
Comfort N, Re DB. 2017. Sex-specific Neurotoxic Effects of Organophosphate Pesticides Across the Life Course. Curr Environ Health Rep 4:392-404; doi:10.1007/s40572-017-0171-y.

Coscollà C, López A, Yahyaoui A, Colin P, Robin C, Poinsignon Q, et al. 2017. Human exposure and risk assessment to airborne pesticides in a rural French community. Science of The Total Environment 584-585:856-868; doi:10.1016/j.scitotenv.2017.01.132.

Costa LG. 2018. Organophosphorus Compounds at 80: Some Old and New Issues. Toxicol Sci 162:2435; doi:10.1093/toxsci/kfx266.

de Gavelle E, de Lauzon-Guillain B, Charles M-A, Chevrier C, Hulin M, Sirot V, et al. 2016. Chronic dietary exposure to pesticide residues and associated risk in the French ELFE cohort of pregnant women. Environment International 92-93:533-542; doi:10.1016/j.envint.2016.04.007.

Dereumeaux C, Saoudi A, Pecheux M, Berat B, de Crouy-Chanel P, Zaros C, et al. 2016. Biomarkers of exposure to environmental contaminants in French pregnant women from the Elfe cohort in 2011. Environment International 97:56-67; doi:10.1016/j.envint.2016.10.013.

Diamond A, Barnett WS, Thomas J, Munro S. 2007. Preschool Program Improves Cognitive Control. Science 318:1387-1388; doi:10.1126/science.1151148.

Eskenazi B, Bradman A, Castorina R. 1999. Exposures of children to organophosphate pesticides and their potential adverse health effects. Environmental Health Perspectives 107:409-419; doi:10.1289/ehp.99107s3409.

Furlong MA, Herring A, Buckley JP, Goldman BD, Daniels JL, Engel LS, et al. 2017. Prenatal exposure to organophosphorus pesticides and childhood neurodevelopmental phenotypes. Environmental Research 158:737-747; doi:10.1016/j.envres.2017.07.023.

Garlantézec R, Monfort C, Rouget F, Cordier S. 2009. Maternal occupational exposure to solvents and congenital malformations: a prospective study in the general population. Occupational and Environmental Medicine 66:456-463; doi:10.1136/oem.2008.041772.

Grahn JA, Parkinson JA, Owen AM. 2008. The cognitive functions of the caudate nucleus. Progress in Neurobiology 86:141-155; doi:10.1016/j.pneurobio.2008.09.004.

Gupta A, Agarwal R, Shukla GS. 1999. Functional impairment of blood-brain barrier following pesticide exposure during early development in rats. Hum Exp Toxicol 18:174-179; doi:10.1177/096032719901800307.

Harari Raul, Julvez Jordi, Murata Katsuyuki, Barr Dana, Bellinger David C., Debes Frodi, et al. 2010. Neurobehavioral Deficits and Increased Blood Pressure in School-Age Children Prenatally Exposed to Pesticides. Environmental Health Perspectives 118:890-896; doi:10.1289/ehp.0901582.

Horton MK, Margolis AE, Tang C, Wright R. 2014. Neuroimaging is a novel tool to understand the impact of environmental chemicals on neurodevelopment. Curr Opin Pediatr 26:230-236; doi:10.1097/MOP.0000000000000074.

Jin Y, Hein MJ, Deddens JA, Hines CJ. 2011. Analysis of Lognormally Distributed Exposure Data with Repeated Measures and Values below the Limit of Detection Using SAS. Ann Occup Hyg 55:97-112; doi:10.1093/annhyg/meq061. 
Jusko TA, van den Dries MA, Pronk A, Shaw Pamela A., Guxens Mònica, Spaan Suzanne, et al. 2019. Organophosphate Pesticide Metabolite Concentrations in Urine during Pregnancy and Offspring Nonverbal IQ at Age 6 Years. Environmental Health Perspectives 127:017007; doi:10.1289/EHP3024.

Luna B, Sweeney JA. 2006. The Emergence of Collaborative Brain Function: fMRI Studies of the Development of Response Inhibition. Annals of the New York Academy of Sciences 1021:296-309; doi:10.1196/annals.1308.035.

Marks AR, Harley Kim, Bradman Asa, Kogut Katherine, Barr Dana Boyd, Johnson Caroline, et al. 2010. Organophosphate Pesticide Exposure and Attention in Young Mexican-American Children: The CHAMACOS Study. Environmental Health Perspectives 118:1768-1774; doi:10.1289/ehp.1002056.

Mortamais M, Chevrier C, Philippat C, Petit C, Calafat AM, Ye X, et al. 2012. Correcting for the influence of sampling conditions on biomarkers of exposure to phenols and phthalates: a 2step standardization method based on regression residuals. Environ Health 11:29; doi:10.1186/1476-069X-11-29.

Mostofsky SH, Schafer JG, Abrams MT, Goldberg MC, Flower AA, Boyce A, et al. 2003. fMRI evidence that the neural basis of response inhibition is task-dependent. Cognitive brain research 17: 419-430.

Nichols T, Hayasaka S. 2003. Controlling the familywise error rate in functional neuroimaging: a comparative review. Statistical Methods in Medical Research 12:419-446; doi:10.1191/0962280203sm341ra.

Ogawa S, Lee TM, Kay AR, Tank DW. 1990. Brain magnetic resonance imaging with contrast dependent on blood oxygenation. Proc Natl Acad Sci U S A 87: 9868-9872.

Raffy G, Mercier F, Blanchard O, Derbez M, Dassonville C, Bonvallot N, et al. 2017. Semi-volatile organic compounds in the air and dust of 30 French schools: a pilot study. Indoor Air 27:114127; doi:10.1111/ina.12288.

Rauh VA, Perera FP, Horton MK, Whyatt RM, Bansal R, Hao X, et al. 2012. Brain anomalies in children exposed prenatally to a common organophosphate pesticide. Proceedings of the National Academy of Sciences 109:7871-7876; doi:10.1073/pnas.1203396109.

Rice D, Barone S. 2000. Critical periods of vulnerability for the developing nervous system: evidence from humans and animal models. Environ Health Perspect 108:511-533; doi:10.1289/ehp.00108s3511.

Rosen ML, Sheridan MA, Sambrook KA, Peverill MR, Meltzoff AN, McLaughlin KA. 2018. The Role of Visual Association Cortex in Associative Memory Formation across Development. J Cogn Neurosci 30:365-380; doi:10.1162/jocn_a_01202.

Ruckart P, Kakolewski Kirsten, Bove Frank J, Kaye Wendy E. 2004. Long-term neurobehavioral health effects of methyl parathion exposure in children in Mississippi and Ohio. Environmental Health Perspectives 112:46-51; doi:10.1289/ehp.6430.

Sagiv SK, Bruno JL, Baker JM, Palzes V, Kogut K, Rauch S, et al. 2019. Prenatal exposure to organophosphate pesticides and functional neuroimaging in adolescents living in proximity to pesticide application. PNAS 201903940; doi:10.1073/pnas.1903940116. 
Silver MK, Shao J, Zhu B, Chen M, Xia Y, Kaciroti N, et al. 2017. Prenatal naled and chlorpyrifos exposure is associated with deficits in infant motor function in a cohort of Chinese infants. Environment International 106:248-256; doi:10.1016/j.envint.2017.05.015.

Slotkin TA, Seidler FJ. 2005. The alterations in CNS serotonergic mechanisms caused by neonatal chlorpyrifos exposure are permanent. Developmental Brain Research 158:115-119; doi:10.1016/j.devbrainres.2005.06.008.

Stoodley CJ, Schmahmann JD. 2009. Functional topography in the human cerebellum: A metaanalysis of neuroimaging studies. Neurolmage 44:489-501; doi:10.1016/j.neuroimage.2008.08.039.

Sudakin DL, Stone DL. 2011. Dialkyl phosphates as biomarkers of organophosphates: The current divide between epidemiology and clinical toxicology. Clinical Toxicology 49:771-781; doi:10.3109/15563650.2011.624101.

Suskauer SJ, Simmonds DJ, Fotedar S, Blankner JG, Pekar JJ, Denckla MB, et al. 2008. Functional magnetic resonance imaging evidence for abnormalities in response selection in attention deficit hyperactivity disorder: differences in activation associated with response inhibition but not habitual motor response. J Cogn Neurosci 20:478-493; doi:10.1162/jocn.2008.20032.

Terry AV. 2012. Functional consequences of repeated organophosphate exposure: Potential noncholinergic mechanisms. Pharmacology \& Therapeutics 134:355-365; doi:10.1016/j.pharmthera.2012.03.001.

Whyatt R M, Barr D B. 2001. Measurement of organophosphate metabolites in postpartum meconium as a potential biomarker of prenatal exposure: a validation study. Environmental Health Perspectives 109:417-420; doi:10.1289/ehp.01109417.

Willcutt EG, Doyle AE, Nigg JT, Faraone SV, Pennington BF. 2005. Validity of the Executive Function Theory of Attention-Deficit/Hyperactivity Disorder: A Meta-Analytic Review. Biological Psychiatry 57:1336-1346; doi:10.1016/j.biopsych.2005.02.006.

Yolton K, Cornelius M, Ornoy A, McGough J, Makris S, Schantz S. 2014. Exposure to neurotoxicants and the development of attention deficit hyperactivity disorder and its related behaviors in childhood. Neurotoxicology and Teratology 44:30-45; doi:10.1016/j.ntt.2014.05.003. 
$\underline{\text { Table }}$

Table 1: Characteristics of participants included in the study.

\begin{tabular}{|c|c|c|}
\hline Characteristics & $n=95$ & Study population \\
\hline & $\mathrm{N}$ & $\%$ \\
\hline \multicolumn{3}{|l|}{ Family characteristics } \\
\hline European origin & 95 & $100 \%$ \\
\hline \multicolumn{3}{|l|}{ Maternal characteristics } \\
\hline $\begin{array}{r}\text { Age } \\
<30 \text { years old } \\
30-35 \text { years old } \\
>35 \text { years old }\end{array}$ & $\begin{array}{l}41 \\
40 \\
14\end{array}$ & $\begin{array}{c}30.4(28.1 ; 33.5)^{\mathrm{a}} \\
43.2 \% \\
42.1 \% \\
14.7 \%\end{array}$ \\
\hline $\begin{array}{r}\text { Body Mass Index } \\
<18.5 \mathrm{~kg} / \mathrm{m}^{2} \\
18.5-25 \mathrm{~kg} / \mathrm{m}^{2} \\
\geq 25 \mathrm{~kg} / \mathrm{m}^{2}\end{array}$ & $\begin{array}{l}10 \\
69 \\
16\end{array}$ & $\begin{array}{l}10.5 \% \\
72.6 \% \\
16.8 \%\end{array}$ \\
\hline $\begin{array}{r}\text { Post-secondary school } \\
2 \text { years or less } \\
\geq 3 \text { years } \\
\text { Missing value }\end{array}$ & $\begin{array}{c}50 \\
44 \\
1\end{array}$ & $\begin{array}{l}53.2 \% \\
46.8 \%\end{array}$ \\
\hline $\begin{array}{r}\text { Occupation at inclusion } \\
\text { no } \\
\text { yes }\end{array}$ & $\begin{array}{c}8 \\
87\end{array}$ & $\begin{array}{c}8.4 \% \\
91.6 \%\end{array}$ \\
\hline $\begin{array}{r}\text { Smoker before inclusion } \\
\text { no } \\
\text { yes }\end{array}$ & $\begin{array}{l}62 \\
33 \\
\end{array}$ & $\begin{array}{l}65.3 \% \\
34.7 \% \\
\end{array}$ \\
\hline $\begin{array}{r}\text { High blood pressure } \\
\text { no } \\
\text { yes }\end{array}$ & $\begin{array}{c}92 \\
3\end{array}$ & $\begin{array}{l}96.8 \% \\
3.2 \%\end{array}$ \\
\hline $\begin{array}{r}\text { Diabetes } \\
\text { no } \\
\text { Missing value }\end{array}$ & $\begin{array}{c}94 \\
1\end{array}$ & $100 \%$ \\
\hline $\begin{array}{r}\text { Fruit and vegetable consumption } \\
<3 \text { portions/day } \\
\geq 3 \text { portions/day }\end{array}$ & $\begin{array}{l}78 \\
17 \\
\end{array}$ & $\begin{array}{l}82.1 \% \\
17.9 \%\end{array}$ \\
\hline $\begin{array}{r}\text { Fish consumption } \\
<\text { twice a month } \\
\geq \text { twice a month }\end{array}$ & $\begin{array}{l}62 \\
33 \\
\end{array}$ & $\begin{array}{l}65.3 \% \\
34.7 \% \\
\end{array}$ \\
\hline Newborn characteristics & & \\
\hline $\begin{array}{r}\text { Sex } \\
\text { Boys } \\
\text { Girls }\end{array}$ & $\begin{array}{l}41 \\
54\end{array}$ & $\begin{array}{l}43.2 \% \\
56.8 \%\end{array}$ \\
\hline $\begin{array}{r}\text { Gestational age } \\
\leq 39 \text { weeks of amenorrhea } \\
>39 \text { weeks of amenorrhea }\end{array}$ & $\begin{array}{l}44 \\
51\end{array}$ & $\begin{array}{l}46.3 \% \\
53.7 \%\end{array}$ \\
\hline $\begin{array}{r}\text { Birth weight } \\
<3000 \mathrm{~g} \\
\geq 3000 \mathrm{~g}\end{array}$ & $\begin{array}{l}12 \\
83\end{array}$ & $\begin{array}{c}3430(3165 ; 3800)^{\mathrm{a}} \\
12.6 \% \\
87.4 \%\end{array}$ \\
\hline $\begin{array}{r}\text { Breastfeeding } \\
\leq 3 \text { months } \\
>3 \text { months }\end{array}$ & $\begin{array}{l}54 \\
41 \\
\end{array}$ & $\begin{array}{c}2(0 ; 5.7) \\
56.8 \% \\
43.2 \%\end{array}$ \\
\hline Child characteristics (at follow-up) & & \\
\hline $\begin{array}{r}\text { Parity } \\
\text { single child } \\
1 \text { sibling } \\
\geq 2 \text { siblings }\end{array}$ & $\begin{array}{l}16 \\
43 \\
36\end{array}$ & $\begin{array}{l}16.8 \% \\
45.3 \% \\
37.9 \% \\
\end{array}$ \\
\hline $\begin{array}{r}\text { Age } \\
10 \text { years old }\end{array}$ & 66 & $\begin{array}{c}10.8(10.6 ; 11.1)^{\mathrm{a}} \\
69.5 \%\end{array}$ \\
\hline
\end{tabular}




\section{Journal Pre-proof}

\begin{tabular}{r|c|c|}
11 years old & 29 & $30.5 \%$ \\
\hline $\begin{array}{r}\text { Educational level } \\
\text { elementary school }\end{array}$ & 69 & $72.6 \%$ \\
junior high school & 26 & $27.4 \%$ \\
\hline Lateralization & & \\
right-hander & 83 & $87.4 \%$ \\
left-hander & 12 & $12.6 \%$ \\
\hline
\end{tabular}

755

756 a.

median

(Q1;

Q3) 
Table 2: Associations between dialkylphosphate levels in maternal urines during pregnancy and activation intensity related to successful inhibition during the Go/No-Go task of their 10-12 years old children (PELAGIE cohort. 2002-2017) (FWER correction at $p<0.05$ ).

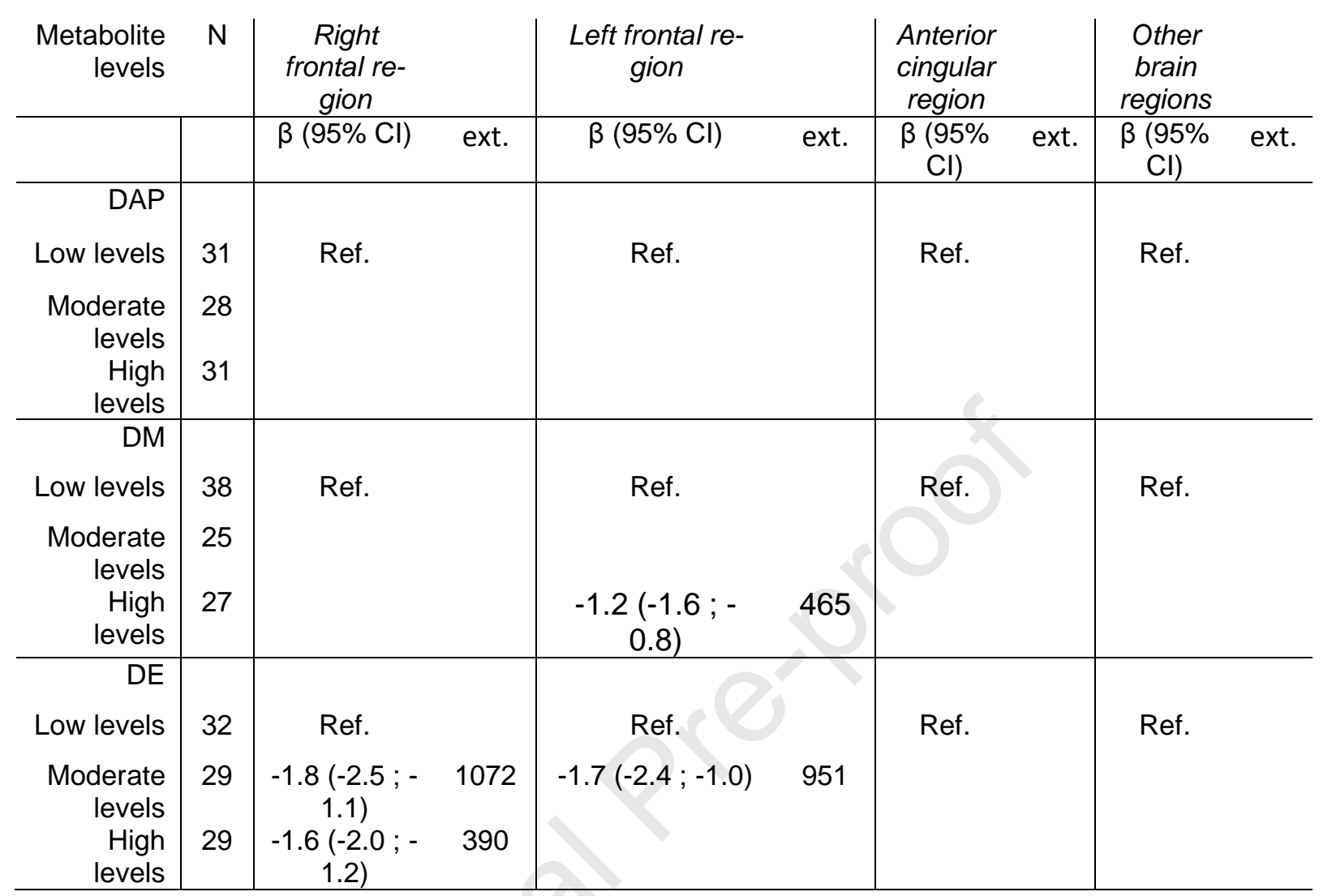

757 Note: DAP: Dialkylphosphate, DE: diethylphosphate, DM: dimethylphosphate

$758 \beta(95 \%$ IC): estimated coefficient [95\% confidence interval]. Empty cell: no statistically significant 759 difference reported in this region.

760 Estimates are provided for clusters presented in Figure 3. All estimates are from mixed-effect gener761 alized linear regression models adjusted for maternal fruit/vegetable consumption $(<3$ portions a 762 day vs $\geq 3$ portions a day) and the duration of breastfeeding ( $<3$ months vs $>3$ months). 
764 Figure legends

Figure 1: Flowchart of inclusions from the PELAGIE cohort $(n=3,421)$ to the present study (n=95).Figure I. Flowchart of inclusions from the PELAGIE cohort $(n=3,421)$ to the present study (n=95).

765 Note: WA: weeks of amenorrhea

766

Figure 2: Associations between OP metabolites levels in maternal urine during pregnancy and performance indicators for the Go/No-Go task of their 10-to 12-year-old children (PELAGIE cohort, 2002-2017) ( $n=92)$.

767 Note: DAP: dialkylphosphate, DE: diethylphosphate, DM: dimethylphosphate

768 All estimates are from linear regression models adjusted for maternal fruit/vegetable consumption $(<$ 7693 portions a day vs $\geq 3$ portions a day) and the duration of breastfeeding ( $<3$ months vs $>3$ months). $* p<0.05,+: 0.05 \leq p<0.10$.

Figure 3: Summary of associations between urinary OP metabolites levels during pregnancy and brain activation during successful inhibition $(n=90) *$.

772 Note: DAP: dialkylphosphate, DE: diethylphosphate, DM: dimethylphosphate, inf.: inferior, L: left, R:

773 right

774 Adjusted for maternal fruit/vegetable consumption ( $<3$ portions a day vs $\geq 3$ portions a day) and the 775 duration of breastfeeding ( $<3$ months vs $>3$ months).

776 *FWER corrected- $p \leq 0.05$ with a one-sided uncorrected- $p \leq 0.01$ threshold. 


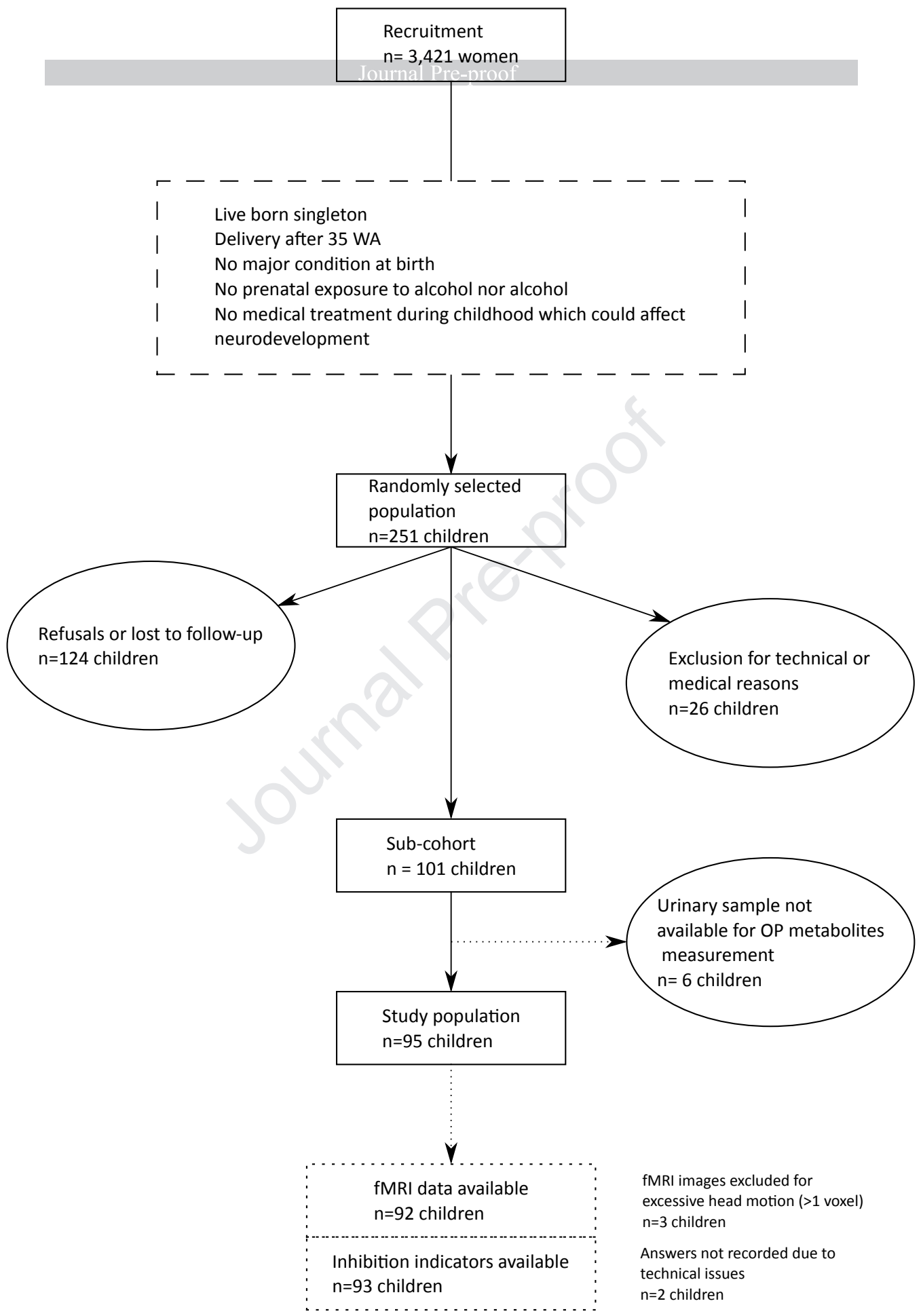


DAP

moderate $(n=29)$

vs. low levels $(n=32)$

$0.33 \quad[-0.49 ; 1.15]$

$0.66 \quad[-1.19 ; 2.51]$

$0.28 \quad[-0.34 ; 0.9]$

$0.24 \quad[-0.59 ; 1.07]$

high ( $n=32)$

vs. low levels $(n=32)$

$0.79[-1.04 ; 2.61]$

$0.33 \quad[-0.34 ; 1.01]$

$0.13(-0.08 ; 0.34)$

continuous log-transformed levels ( $n=93$ )

\section{DM}

moderate $(n=30)$

vs. low levels $(n=32)$

vs. low levels $(n=32)$

$0.73 \quad[-1.17 ; 2.63]$

$0.43 \quad[-0.22 ; 1.08]$

continuous log-transformed

levels ( $n=93$ )

\section{DE}

moderate $(n=27)$

vs. low levels $(n=39)$

high $(n=27)$

vs. low levels $(n=39)$

$0.04 \quad[-1.66 ; 1.73]$

$-0.36 \quad[-0.95 ; 0.23]$

continuous log-transformed levels ( $n=93$ )

$-0.02(-0.13 ; 0.08)$

All Boys Girls

$-0.76 \quad[-1.56 ; 0.03]$

$-0.48 \quad[-2.09 ; 1.14]$

$-0.92[-1.54 ;-0.29]=$

$-0.19 \quad[-0.98 ; 0.6]$

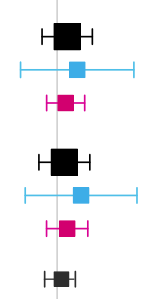

$0.01 \quad[-0.07 ; 0.1]$

$-0.03 \quad[-0.21 ; 0.14]$

$0.03 \quad[-0.05 ; 0.12]$

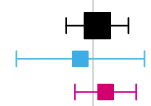

$-0.02[-0.11 ; 0.07]$

$-0.04[-0.21 ; 0.14]$

$-0.05[-0.14 ; 0.04]$

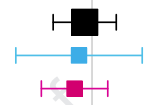

$-0.01(-0.03 ; 0.01)$
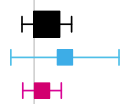

$-0.06 \quad[-0.22 ; 0.11]$

$0.03 \quad[-0.05 ; 0.11]$

$-0.04[-0.13 ; 0.04]$

$-0.02 \quad[-0.2 ; 0.16]$

$-0.09[-0.18 ;-0.01] *$

Departure from linearity
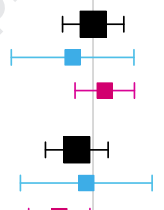

$H$

Departure from linearity
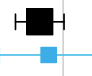

$\mathrm{H}$

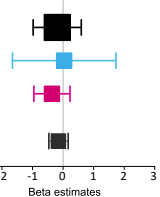

$0.08[0 ; 0.16]+$

$0.09[-0.06 ; 0.24]$

$0.06 \quad[-0.03 ; 0.15]$

$0.03 \quad[-0.05 ; 0.11]$

$0.03 \quad[-0.13 ; 0.19]$

$0.03 \quad[-0.06 ; 0.12]$

$0(-0.01 ; 0.02)$

Beta estimates
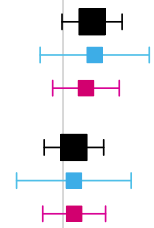

$\square$

$\begin{array}{llllll}-0.25 & -0.15 & -0.05 & 0.05 & 0.15 & 0.25\end{array}$ Beta estimates

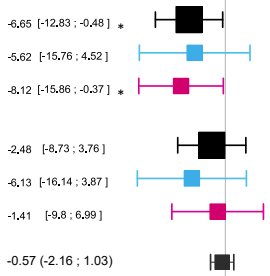

$-5.59[-11.71 ; 0.53]+$

$-5.27[-15.03 ; 4.49]$

$-7.36[-15.23 ; 0.51]+$

$+$

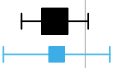

$-0.31 \quad[-6.57 ; 5.95]$

$-6.10[-16.58 ; 4.38]$

$1.22 \quad[-6.91 ; 9.35]$

$-0.41(-2.14 ; 1.33)$

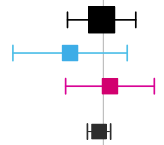

$0.72 \quad[-5.48 ; 6.93]$

$-7.33[-15.98 ; 1.33]$

$8.23[-0.17 ; 16.63]+$

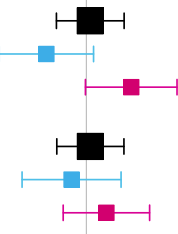

$3.68[-4.24 ; 11.61]$

$-0.15(-0.96 ; 0.67)$

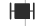




\begin{tabular}{|c|c|c|c|}
\hline & Low level & Moderate level (vs low) & High level (vs low) \\
\hline DAP & Reference & No statistically significant difference & No statistically significant difference \\
\hline DM & Reference & No statistically significant difference & Superior view L. inf. frontal \\
\hline DE & Reference & Superior view..... L. frontal & \\
\hline
\end{tabular}

